\title{
Low temperature plasma enhanced deposition of GaP films on Si substrate
}

Alexander S. Gudovskikh, Ivan A. Morozov, Alexander V. Uvarov, Dmitriy A. Kudryashov, Ekaterina V. Nikitina, Anton S. Bukatin, Vladimir N. Nevedomskiy, and Jean-Paul Kleider

Citation: Journal of Vacuum Science \& Technology A 36, 021302 (2018); doi: 10.1116/1.4999409

View online: https://doi.org/10.1116/1.4999409

View Table of Contents: http://avs.scitation.org/toc/jva/36/2

Published by the American Vacuum Society

\section{Articles you may be interested in}

Synergistic interactions of $\mathrm{H}_{2}$ and $\mathrm{N}_{2}$ with molten gallium in the presence of plasma Journal of Vacuum Science \& Technology A: Vacuum, Surfaces, and Films 36, 021303 (2018); $10.1116 / 1.5004540$

Characterization of particle generated during plasma-enhanced chemical vapor deposition on amorphous carbon layer using particle beam mass spectrometer Journal of Vacuum Science \& Technology A: Vacuum, Surfaces, and Films 36, 021506 (2018); $10.1116 / 1.5000087$

Nucleation mechanism during $\mathrm{WS}_{2}$ plasma enhanced atomic layer deposition on amorphous $\mathrm{Al}_{2} \mathrm{O}_{3}$ and sapphire substrates

Journal of Vacuum Science \& Technology A: Vacuum, Surfaces, and Films 36, 01 A105 (2018);

$10.1116 / 1.5003361$

Sub-damage-threshold plasma etching and profile tailoring of Si through laser-stimulated thermal desorption Journal of Vacuum Science \& Technology A: Vacuum, Surfaces, and Films 36, 021301 (2018); $10.1116 / 1.4991586$

Plasma enhanced atomic layer deposition of aluminum sulfide thin films Journal of Vacuum Science \& Technology A: Vacuum, Surfaces, and Films 36, 01 A113 (2018); $10.1116 / 1.5003339$

Low temperature plasma enhanced deposition approach for fabrication of microcrystalline GaP/Si superlattice Journal of Vacuum Science \& Technology A: Vacuum, Surfaces, and Films 36, 02 D408 (2018); 10.1116/1.5018259

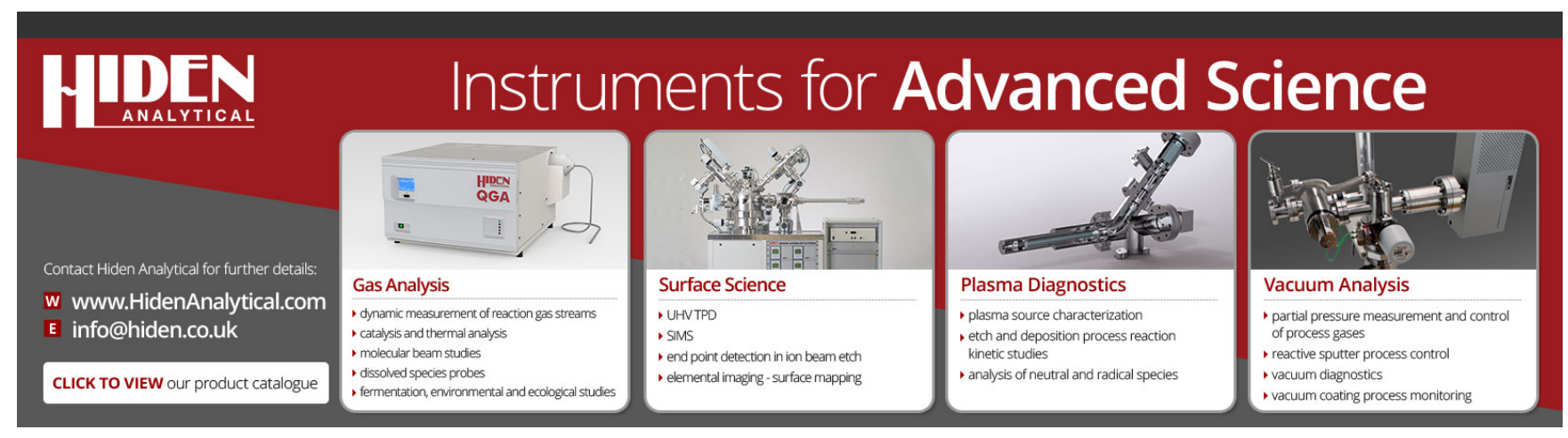




\title{
Low temperature plasma enhanced deposition of GaP films on Si substrate
}

\author{
Alexander S. Gudovskikh, ${ }^{\text {a) }}$ Ivan A. Morozov, Alexander V. Uvarov, Dmitriy A. Kudryashov, \\ Ekaterina V. Nikitina, and Anton S. Bukatin \\ Nanotechnology Centre, St. Petersburg Academic University RAS, Hlopina Str. 8/3, St.-Petersburg 194021, Russia \\ Vladimir N. Nevedomskiy \\ A. F. Ioffe Physical-Technical Institute RAS, Polytechnicheskaya Str. 26, St.-Petersburg 194021, Russia \\ Jean-Paul Kleider \\ GeePs, Group of Electrical Engineering-Paris, CNRS, CentraleSupélec, Univ. Paris-Sud, \\ Université Paris-Saclay, Sorbonne Universités, UPMC Univ Paris 06, 11 rue Joliot-Curie, \\ 91192 Gif-sur-Yvette Cedex, France
}

(Received 8 August 2017; accepted 13 November 2017; published 8 December 2017)

\begin{abstract}
Amorphous and microcrystalline $\mathrm{GaP}$ films were deposited on $\mathrm{Si}$ substrates by time modulated plasma enhanced deposition from trimethylgallium and phosphine using constant hydrogen plasma at a temperature of $250-380^{\circ} \mathrm{C}$. Amorphous GaP films obtained at constant low radio-frequency (RF) power $(20 \mathrm{~W})$ mode exhibit the broad feature at $350-360 \mathrm{~cm}^{-1}$ and a shoulder at $370-390 \mathrm{~cm}^{-1}$ in Raman spectra. Amorphous films have smooth surface with root-mean-square (RMS) roughness decreasing from 0.9 to $0.2 \mathrm{~nm}$ with increasing deposition temperature from 250 to $380^{\circ} \mathrm{C}$. Small amounts of 3-5 nm GaP nanocrystal inclusions in the amorphous matrix are formed at $380^{\circ} \mathrm{C}$. An increase of RF power to $100 \mathrm{~W}$ during Ga and P deposition steps leads to the formation of a GaP crystalline phase as confirmed by transmission electron microscopy. Two peaks in the Raman spectra at 365 and $402 \mathrm{~cm}^{-1}$, which correspond to GaP TO-LO duplet, were observed in this case. However, the microcrystalline GaP layers have rough surface with RMS roughness of $6 \mathrm{~nm}$. A critical role of the hydrogen plasma for GaP growth mechanism is demonstrated. Indeed an effect of the phosphorous accumulation in the deposition chamber during phosphine plasma assisted decomposition step is shown. The hydrogen plasma treatment after P deposition step allows one to avoid an influence of excess phosphorous to the growth process providing a way to obtain ALD like growth of GaP with good thickness uniformity. Published by the AVS. https://doi.org/10.1116/1.4999409
\end{abstract}

\section{INTRODUCTION}

Heterostructures with $\mathrm{GaP}$ layer grown on $\mathrm{Si}$ substrates are of great interest for optoelectronic devices integrated with silicon, in particular, for solar cells. GaP has the smallest lattice mismatch beyond III-V binary compounds (less $0.4 \%$ ) being the best candidate for nucleation (buffer) layer providing conditions for low defect density at the interface with the Si substrate. ${ }^{1} \mathrm{GaP}$ has a gap of $2.26 \mathrm{eV}$ fitting requirements for a wide gap emitter of $\mathrm{GaP} / \mathrm{Si}$ heterojunction solar cells, which according to simulations could have an advantage of more than $1 \%$ of efficiency compared to passivated emitter and rear cells made of p-type $\mathrm{Si}$ wafers, ${ }^{2}$ which are still of interest, in particular, for low orbit space applications due to better radiation hardness. ${ }^{3}$ Recently, promising results have been obtained using $\mathrm{n}-\mathrm{GaP}$ window for Si n-p homojunctions. ${ }^{4}$ However, GaP layers are commonly grown by epitaxial techniques such as molecular beam epitaxy $(\mathrm{MBE})^{5,6}$ and metal organic vapor-phase epitaxy (MOVPE) ${ }^{7-9}$ which require relatively high temperatures $\left(500-800^{\circ} \mathrm{C}\right)$. Until now, the photovoltaic performance of $\mathrm{GaP} / \mathrm{Si}$ heterojunctions obtained by epitaxy $\mathrm{y}^{4,10,11}$ is far from that of high efficiency Si solar cells. The main problem, especially for structures with anisotype heterojunctions (n$\mathrm{GaP} / \mathrm{p}-\mathrm{Si}$ ), can be related to the high growth temperature, which affects the $\mathrm{GaP} / \mathrm{Si}$ interface quality. ${ }^{12}$ The use of high

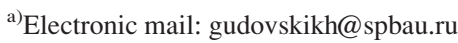

temperatures could lead to interdiffusion of group-III and -V atoms into $\mathrm{Si}$ and opposite, which act as dopants affecting the electrical properties of heterojunctions, and it can also promote the fast diffusion of species that can degrade the carrier lifetime in $\mathrm{c}-\mathrm{Si}^{13}$

In this paper, we explore a low temperature (less than $400^{\circ} \mathrm{C}$ ) technological approach for the growth of III-V compounds on Si substrates using plasma-enhanced atomic layer deposition (PE-ALD) approach. The PECVD related lowtemperatures technology could provide a lot of advantages for PV mass production such as large area, high throughput, low price of the equipment, and the process. Low temperature ALD is becoming widely used in photovoltaics for deposition of dielectric antireflection and passivation layers (commonly $\mathrm{Al}_{2} \mathrm{O}_{3}$ ) on the silicon surface ${ }^{14}$ while only few reports on plasma deposition of III-V semiconductors at low temperature could be found. However, the first report on plasma enhanced growth at 300 and $350{ }^{\circ} \mathrm{C}$ of polycrystalline $\mathrm{GaN}$ and amorphous $\mathrm{GaP}$ films, ${ }^{15}$ respectively, is dated by 1978 . Recently, the GaN layers containing small crystallites dispersed in an amorphous matrix were grown on $\mathrm{Si}$ using PE-ALD in the temperature range of $185-385^{\circ} \mathrm{C} .{ }^{16}$ Our preliminary results on plasma enhanced deposition of amorphous $\mathrm{GaP}$ at $350{ }^{\circ} \mathrm{C}$ have demonstrated promising passivation properties of $\mathrm{GaP} / \mathrm{Si}$ heterostructures when the phosphorus and gallium atom source flows were alternatively changed. ${ }^{17}$ However, the obtained deposition rate of 
TABLE I. Parameters of the process steps: time, gas flows, and RF power.

\begin{tabular}{|c|c|c|c|c|c|c|c|c|c|}
\hline \multirow[b]{3}{*}{ Step } & \multicolumn{4}{|c|}{ Constant RF power $(20 \mathrm{~W})$ mode } & \multicolumn{5}{|c|}{ Pulsed RF power mode } \\
\hline & \multirow[b]{2}{*}{$\mathrm{t}(\mathrm{s})$} & \multicolumn{3}{|c|}{ Gas flow (sccm) } & \multirow[b]{2}{*}{$\mathrm{t}(\mathrm{s})$} & \multicolumn{3}{|c|}{ Gas flow (sccm) } & \multirow[b]{2}{*}{$\mathrm{RF}(\mathrm{W})$} \\
\hline & & $\mathrm{PH}_{3}$ & $\mathrm{H}_{2}$ & $\mathrm{TMG} / \mathrm{H}_{2}$ & & $\mathrm{PH}_{3}$ & $\mathrm{H}_{2}$ & $\mathrm{TMG} / \mathrm{H}_{2}$ & \\
\hline P step & $3-5$ & 50 & 50 & - & $2-3$ & 50 & 50 & - & 100 \\
\hline $\mathrm{H}$ plasma treatment & - & - & - & - & $0-5$ & - & 100 & - & 100 \\
\hline Purge & 10 & - & 100 & - & 7 & - & 100 & - & 20 \\
\hline Ga step & $5-10$ & - & 30 & 70 & $3-5$ & - & 30 & 70 & 100 \\
\hline $\mathrm{H}$ plasma treatment & - & - & - & - & $0-2$ & - & 100 & - & 100 \\
\hline Purge & 10 & - & 100 & - & $7-9$ & - & 100 & - & 20 \\
\hline
\end{tabular}

$11.6 \mathrm{~nm} /$ cycle means that the ALD growth mode was not reached. Moreover, Ar plasma, which was used for plasma ignition and discharge, produces radiation defects in Si mitigating the advantage of low-temperature approach. Thus, PE-ALD like technique with hydrogen plasma is used in this study.

\section{EXPERIMENT}

The time modulated plasma enhanced deposition (PEALD like approach) was realized using a standard PECVD setup with capacitively coupled plasma (Oxford Plasmalab 100) supplied with phosphine $\left(\mathrm{PH}_{3}\right)$ and trimethylgallium (TMG) lines for sources of phosphorus and gallium, respectively. Hydrogen was used as a gas carrier for TMG. The hydrogen pressure was 2 bar while the temperature of the TMG cylinder was kept at $3{ }^{\circ} \mathrm{C}$. Silicon substrates with (001) orientation were used for $\mathrm{GaP}$ deposition. At the initial stage, the native oxide was removed from the Si surface by HF-dip (10\%) immediately before loading to the PECVD chamber (via a load-lock system). The substrates were heated to 250-380 ${ }^{\circ} \mathrm{C}$ during $20-30 \mathrm{~min}$ in the vacuum chamber. The total time between HF dip and start of GaP layer deposition process does not exceed $40 \mathrm{~min}$. The ultimate pressure was provided by BOC Edwards iH600 dry vacuum pump, and was estimated to be less 0.1 mTorr (below measurement limit of Pirani gauge).

In order to avoid the Ar plasma influence to Si substrate, the process was performed with continuous $\mathrm{H}_{2}$ plasma discharge during deposition and purge cycles. No evacuation cycles were used because of the difficult plasma ignition of hydrogen rich gas mixture. Due to specific features of our PECVD setup, the purge step should be at least $7 \mathrm{~s}$ for full gas exchange and the minimal time of any step is $2 \mathrm{~s}$ to provide stable program operation. Total gas flow and gas pressure were always kept constant and were equal to $100 \mathrm{sccm}$ and 350 mTorr, respectively. Stable gas dynamic conditions with minimal throttle valve adjustment were reached.

First, the deposition of a series of GaP layers was carried out with temperature variation from 250 to $380{ }^{\circ} \mathrm{C}$ and at a power of $20 \mathrm{~W}$ (corresponds to a power density of $0.03 \mathrm{~W} /$ $\mathrm{cm}^{2}$ ) which is the minimal value required for stable plasma RF (13.56 MHz) discharge. The parameters of each step are presented in Table I. Then, the deposition with pulsed RF power increase to $100 \mathrm{~W}\left(0.14 \mathrm{~W} / \mathrm{cm}^{2}\right)$ during the precursor decomposition and short treatment in hydrogen plasma was performed at the temperature of $380^{\circ} \mathrm{C}$. The total number of cycles for each process was equal to 200 .

The layer morphology and thickness were determined using scanning electron microscopy (SEM) (SUPRA 25 Zeiss) and atomic force microscopy (AFM) (BioScope Catalyst Bruker). The structural properties were studied by Raman spectroscopy using Horiba Jobin Yvon LABRAM HR 800 spectrometer with a laser excitation at $532 \mathrm{~nm}$ and by transmission electron microscopy (TEM) (JEOL JEM 2100F) with $200 \mathrm{kV}$ acceleration voltages. Optical emission spectroscopy (OES) was used for in situ gas content analysis using Solar Laser Systems S100 spectrometer.

\section{RESULTS AND DISCUSSION}

\section{A. Constant RF power mode}

According to X-ray fluorescence measurements, the deposited films content $\mathrm{Ga}$ and $\mathrm{P}$ atoms while no impurities could be detected because of low sensitivity of this technique to thin films. SEM [Fig. 1(a)] and TEM [Fig. 1(b)] demonstrate that GaP films deposited with a constant RF power of $20 \mathrm{~W}$ are homogeneous with a smooth surface and sharp $\mathrm{GaP} / \mathrm{Si}$ interface. The selected area electron diffraction (SAED) pattern of the GaP film obtained by TEM [inset of Fig. 1(b)] exhibits intensive dots corresponding to diffraction from $\mathrm{Si}$ substrate and diffused ring (halo) at (111) plan indicating a dominant amorphous phase of $\mathrm{GaP}$.

The growth per cycle for the $\mathrm{GaP}$ layers grown at $350^{\circ} \mathrm{C}$ and above was about $0.25 \pm 0.02 \mathrm{~nm} /$ cycle, indicating the
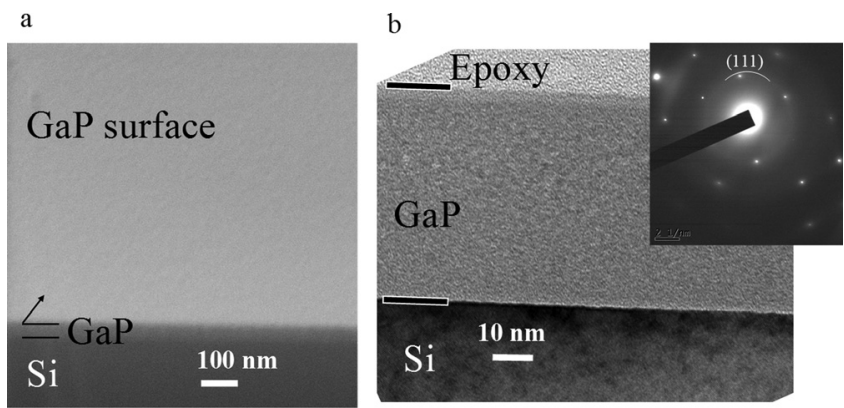

FIG. 1. SEM $20^{\circ}$ tilt (a) and TEM bright field (b) cross section images of the $\mathrm{GaP}$ film grown on $\mathrm{Si}$ at $380^{\circ} \mathrm{C}$ with constant $\mathrm{RF}$ power $(20 \mathrm{~W})$ mode. SAED pattern by TEM is presented in the inset. 

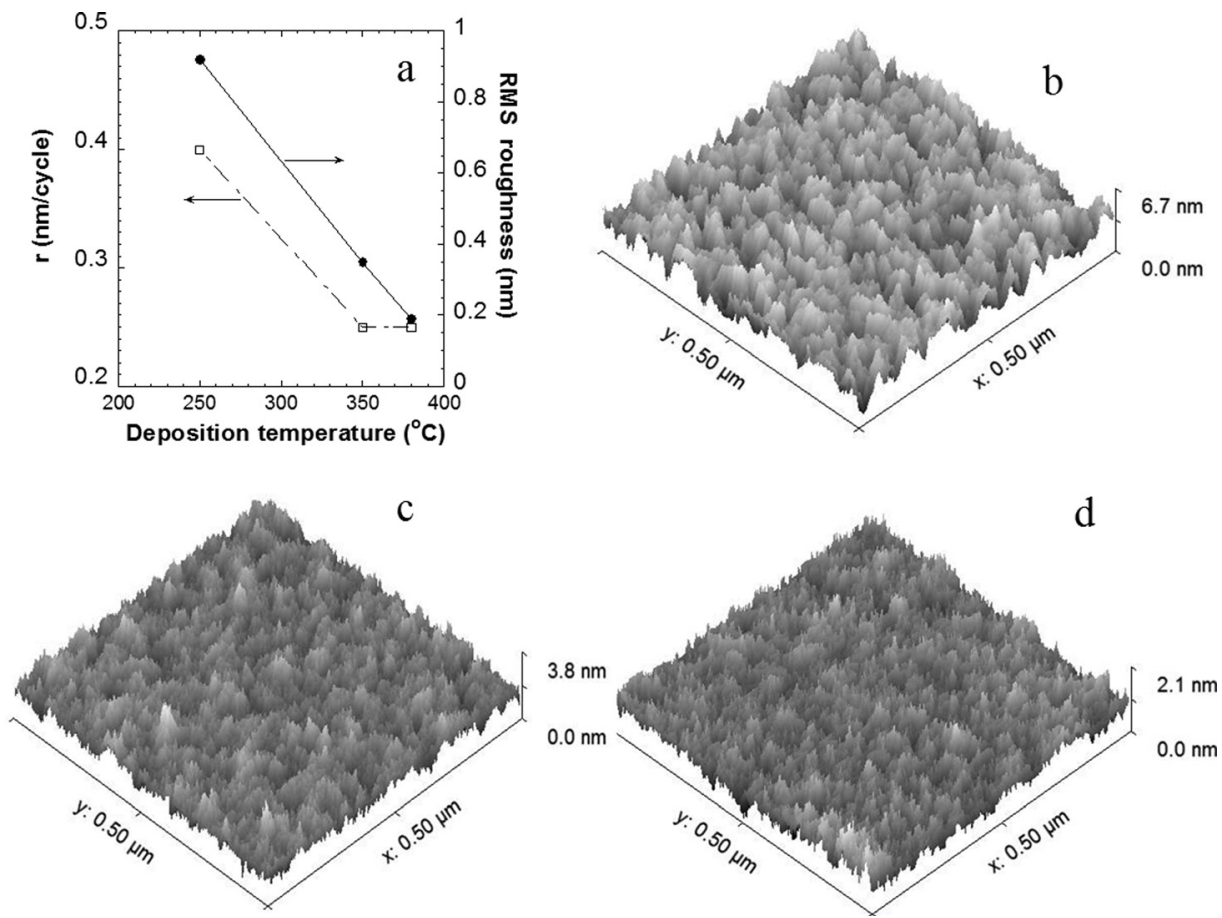

FIG. 2. Temperature dependence of the deposition rate (r) and RMS roughness (a) and surface topology by AFM for GaP deposited at $250^{\circ} \mathrm{C}(\mathrm{b}), 350{ }^{\circ} \mathrm{C}(\mathrm{c})$, and $380^{\circ} \mathrm{C}(\mathrm{d})$.

growth of approximately one $\mathrm{GaP}$ monolayer $(0.275 \mathrm{~nm})$ per cycle [Fig. 2(a)]. Thus, one monolayer per cycle growth mode was achieved using hydrogen plasma in contrary to results obtained with argon plasma $\left(1-1.6 \mathrm{~nm} /\right.$ cycle for $\left.350^{\circ} \mathrm{C}\right)$. For $250^{\circ} \mathrm{C}$, the growth per cycle was about $0.4 \mathrm{~nm} /$ cycle. The surface topography measured by AFM strongly depends on the growth temperature (Fig. 2). The root-mean-square (RMS) roughness decreased from $0.92 \mathrm{~nm}$ for $250^{\circ} \mathrm{C}$ to $0.19 \mathrm{~nm}$ for $380^{\circ} \mathrm{C}$.

The Raman spectra presented in Fig. 3 for GaP layers deposited on $\mathrm{Si}$ substrates at different temperatures exhibit the broad feature at $350-360 \mathrm{~cm}^{-1}$, which corresponds to GaP

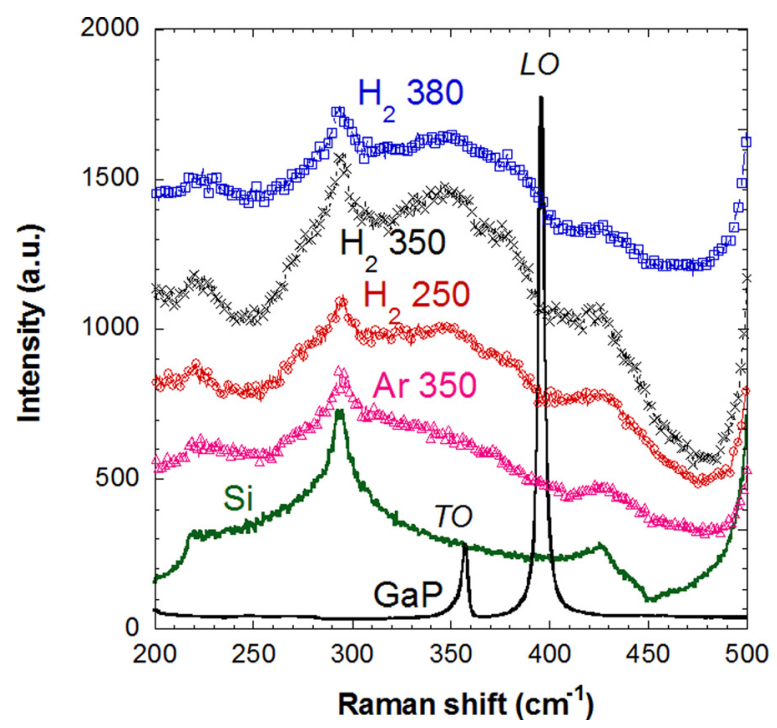

FIG. 3. (Color online) Raman spectra of GaP deposited on Si with constant $\mathrm{RF}$ power at different temperatures. Spectra of $\mathrm{Si}$ and $\mathrm{GaP}$ substrates are also presented.
$\mathrm{TO}(\mathrm{X})-\mathrm{TO}(\mathrm{L})$ peak and a shoulder at $370-390 \mathrm{~cm}^{-1}$. Such behavior of Raman spectra indicates an amorphous structure of the GaP films. ${ }^{18}$ An amorphous structure of PECVD GaP films grown at $350^{\circ} \mathrm{C}$ was also reported in Ref. 15 . We should note that the shoulder at $370-390 \mathrm{~cm}^{-1}$ becomes more pronounced when the deposition temperature is increased, and it shifts toward the GaP LO peak position $\left(402 \mathrm{~cm}^{-1}\right)$, indicating better structural properties. Indeed, a formation of GaP nanocrystals was observed by HRTEM in the layers deposited at $380^{\circ} \mathrm{C}$. Low fraction of $2-3 \mathrm{~nm}$ size ordered inclusions embedded in amorphous GaP matrix could be selected in the HRTEM image presented in Fig. 4.

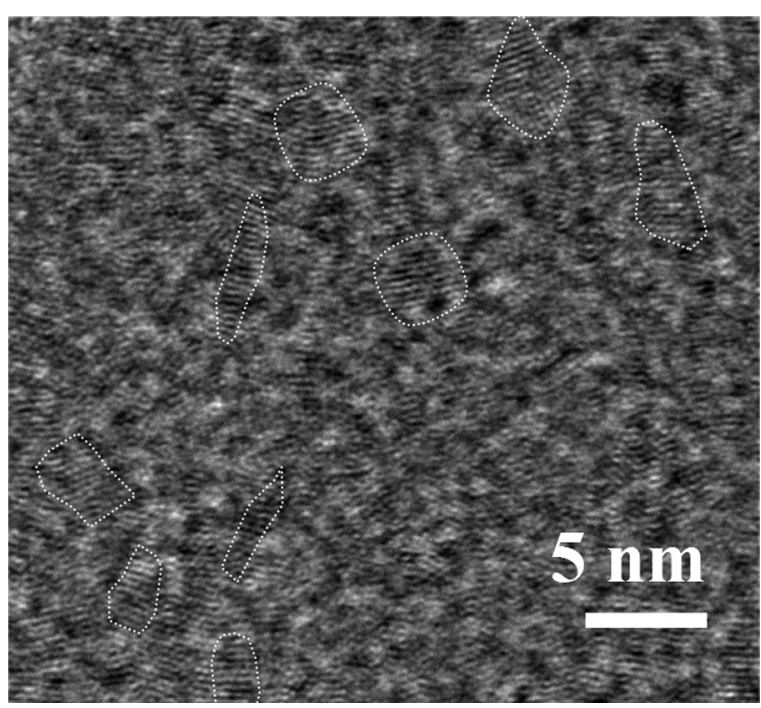

FIg. 4. HRTEM image of GaP grown at $380^{\circ} \mathrm{C}$ with constant RF power $(20 \mathrm{~W})$ mode. Several examples of GaP ordered areas are marked by dot contours. 


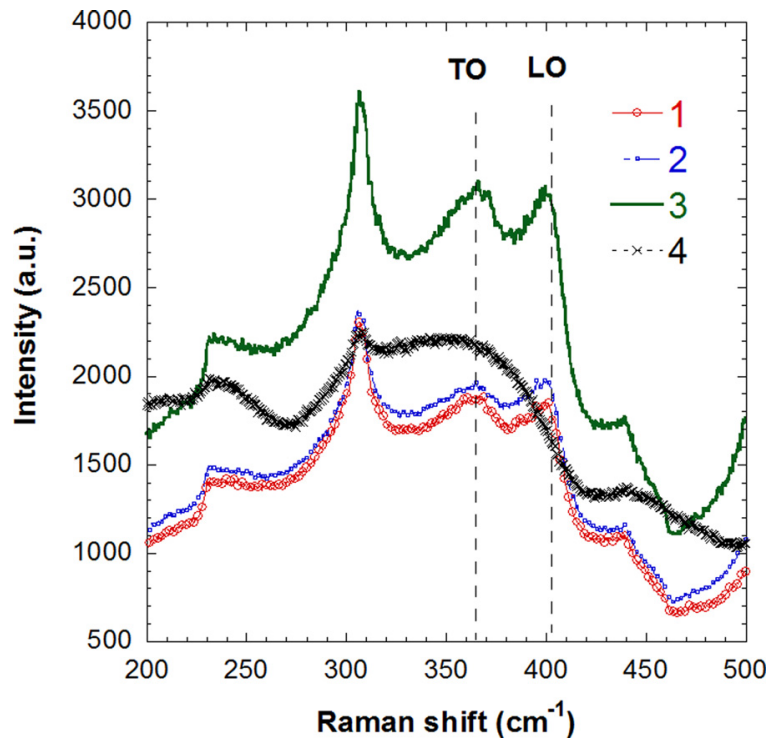

FIG. 5. (Color online) Raman spectra of GaP deposited on Si with pulsed RF power $\left(100 \mathrm{~W}\right.$ ) during $\mathrm{Ga}$ and $\mathrm{P}$ deposition steps: without $\mathrm{H}_{2}$ plasma treatment (1), with $\mathrm{H}_{2}$ plasma (100 W) treatment step after $\mathrm{Ga}$ and $\mathrm{P}$ deposition steps (2), with $\mathrm{H}_{2}$ plasma ( $\left.100 \mathrm{~W}\right)$ treatment step after $\mathrm{P}$ deposition step only (3). GaP deposited at low RF power (20 W) during Ga and P deposition steps but with $\mathrm{H}_{2}$ plasma $(100 \mathrm{~W})$ treatment step after $\mathrm{Ga}$ and $\mathrm{P}$ deposition step (4).

Obviously higher deposition temperature is required to reach a successful surface migration of the deposited atoms for formation of a GaP crystalline phase. However, the deposition temperature of $380^{\circ} \mathrm{C}$ approaches the practical limit of our setup $\left(400^{\circ} \mathrm{C}\right)$ being also close to a temperature limit for the most commonly used plasma-enhanced equipment. Moreover, further temperature increase is undesirable because higher temperature could affect the electronic properties of the $\mathrm{GaP} / \mathrm{Si}$ interface and $\mathrm{Si}$ wafers due to interdiffusion.

\section{B. Pulsed RF power mode}

To enhance the surface migration of adsorbed atoms a pulsed increase of the RF power to $100 \mathrm{~W}$ during Ga and $\mathrm{P}$ deposition steps was proposed. Also the possibility to enhance the surface migration by an additional short hydrogen treatment step at increased RF power introduced immediately after $\mathrm{Ga}$ and $\mathrm{P}$ deposition steps was explored. The RF power during purge steps was decreased to the minimum value $(20 \mathrm{~W})$, which enables to hold the glow discharge and to minimize the influence of hydrogen plasma to Si. The Raman spectra for a $\mathrm{GaP}$ film deposited with pulsed $\mathrm{RF}$ power mode are presented in Fig. 5. Two clear peaks at 365 and $402 \mathrm{~cm}^{-1}$ could be observed in the Raman spectra for the layers grown with increased RF power during Ga and $\mathrm{P}$ deposition steps. The peak positions correspond to the GaP TO-LO duplet ${ }^{19}$ revealing the formation of a GaP crystalline phase. The study of structural properties by TEM demonstrates that $\mathrm{GaP}$ films are microcrystalline (Fig. 6). The selected area electron diffraction (SAED) pattern of the GaP film obtained by TEM confirms the presence of a GaP crystalline phase in the layer [Fig. 6(b)]. Intensive dots in SAED pattern correspond to diffraction from Si substrate, while the sharp rings correspond to (111), (220), and (311) reflections of disoriented $\mathrm{GaP}$ crystals. However, high intensive areas within the diffraction rings indicate a preferred orientation of GaP crystals. A significant crystalline fraction in $\mathrm{GaP}$ films grown with enhanced RF power is observed in the HRTEM image presented in Fig. 6(c) where disoriented GaP grains of few nanometers size could be selected. The formation of grains leads to rough surface of the GaP film deposited at the pulsed RF power mode as illustrated by SEM and AFM in Fig. 7. The RMS roughness is within the range of $5.87-5.92 \mathrm{~nm}$.

When only the short hydrogen treatment step with increased RF power $(100 \mathrm{~W})$ was introduced immediately after low power $(20 \mathrm{~W}) \mathrm{Ga}$ and $\mathrm{P}$ deposition steps the deposited films were amorphous as indicated by Raman spectra (Fig. 5) with smooth surface (RMS roughness $<1 \mathrm{~nm}$ ). However, the pulsed $\mathrm{H}_{2}$ plasma treatment step strongly affects the growth per cycle and thickness uniformity. Indeed, introduction of $\mathrm{H}_{2}$ plasma treatment after Ga deposition step leads to the increase of growth per cycle with deposition step time (Fig. 8), which significantly surpasses one GaP monolayer per cycle. The thickness nonuniformity increases in this case up to $50 \%$ for 3 in. wafer. On the contrary, introduction of $\mathrm{H}_{2}$ plasma treatment after $\mathrm{P}$ deposition step leads to the saturation of the deposition rate with the rise of the deposition step time as for $\mathrm{Ga}$ as well as for P (Fig. 8). The deposition rate saturates at approximately one monolayer of GaP per cycle level. The thickness

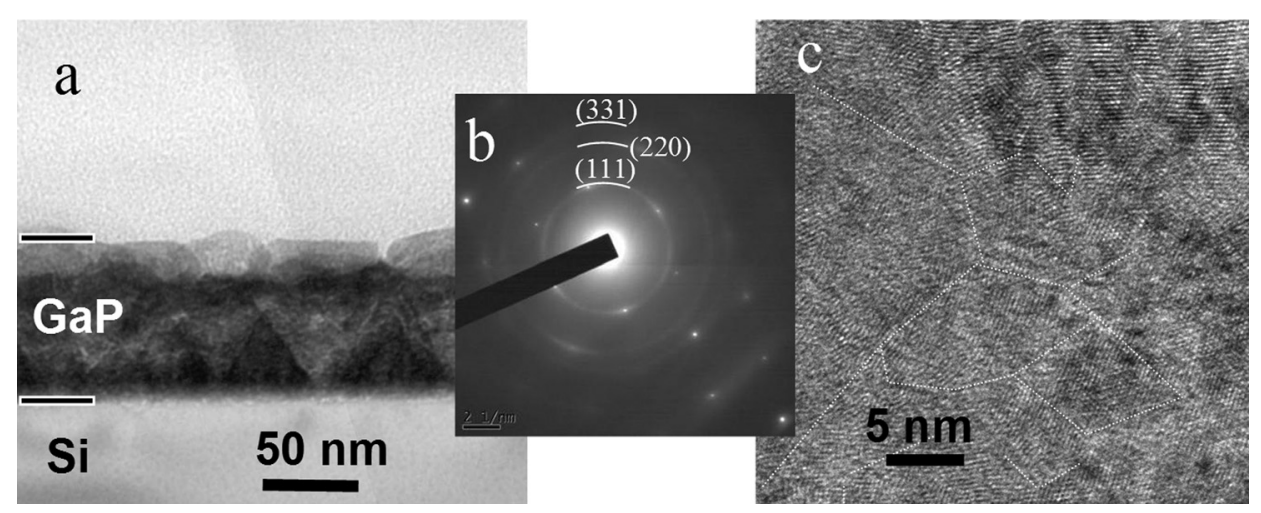

FIG. 6. TEM cross section view (bright field contrast) (a), SAED pattern (b) and HRTEM of GaP grown on Si with pulsed RF power (100 W) during deposition steps. The boundaries between disoriented $\mathrm{GaP}$ sections are selected by the eye. 

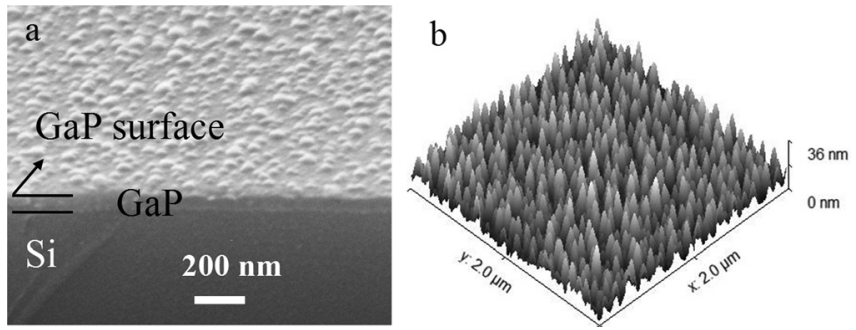

FIG. 7. SEM $20^{\circ}$ tilt cross section image (a) and surface morphology by $\mathrm{AFM}$ (b) for GaP grown on $\mathrm{Si}$ with pulsed RF power $(100 \mathrm{~W})$ during deposition steps.

uniformity was extremely improved in this mode being within the range of $\pm 5 \%$.

To analyze the influence of $\mathrm{H}_{2}$ plasma treatment one should take into account two possible processes. The first one is related to gas mixture changing time because precursor residues could continue to react during the $\mathrm{H}_{2}$ plasma treatment step. The second is related to the possible interaction between phosphorous and $\mathrm{H}_{2}$ plasma. In particular, a red phosphorous could be condensed at the walls of the deposition chamber during $\mathrm{PH}_{3}$ plasma decomposition. ${ }^{20}$ This excess phosphorous should remain in the chamber even after a full gas mixture exchange. However, then the phosphorous is etched by $\mathrm{H}_{2}$ plasma during $\mathrm{Ga}$ deposition and subsequent $\mathrm{H}_{2}$ plasma treatment steps. In this case the formed phosphorous precursors $\left(\mathrm{PH}_{\mathrm{x}}\right)$ would interact with Ga precursors leading to conventional PECVD growth of GaP. Therefore, the growth per cycle could excess one monolayer per cycle with a strong spatial nonuniformity because $\mathrm{P}$ etching from the chamber walls provides nonhomogeneous gas content.

\section{Hydrogen plasma treatment}

Optical emission spectroscopy (OES) was used for in situ examination of the processes during hydrogen plasma treatment. The measured OES spectra of $\mathrm{H}_{2}$ and $\mathrm{PH}_{3}$ plasma are presented in Fig. 9. The pure hydrogen plasma has the most intensive $\mathrm{H}_{\alpha}$ line (from Balmer series) at $656 \mathrm{~nm}$ caused by emission of atomic hydrogen. The short wavelength lines $\mathrm{H}_{\beta}$ and $\mathrm{H}_{\gamma}$ at 486 and $434 \mathrm{~nm}$ have lower intensity. There are also spectral lines of molecular hydrogen at $600 \mathrm{~nm}$ range called Fulcher $\alpha$ band. ${ }^{21}$ Thus, the $\mathrm{H}_{\alpha}$ line was used to control the hydrogen atom concentration in the plasma.

When phosphine is added to the hydrogen plasma it takes a green color due to continuous emission band of $\mathrm{PH}_{3}$ molecules in the range of $450-650 \mathrm{~nm}$. Phosphine plasma has also lines at 341, 666 and $717 \mathrm{~nm}$, which correspond to emission lines of $\mathrm{PH}$ and $\mathrm{PH}_{2}$ radicals. The most intense $\mathrm{PH}_{2} 666 \mathrm{~nm}$ line is of particular interest, because neither molecular nor atomic hydrogen emission lines appear at this wavelength, allowing one to extract information about the concentration of $\mathrm{PH}_{2}$ radicals and atomic hydrogen in the $\mathrm{PH}_{3} / \mathrm{H}_{2}$ plasma.

The time dependence of the $\mathrm{PH}_{2}$ and $\mathrm{H}_{\alpha}$ lines during deposition process with pulsed $\mathrm{RF}$ power increase and $\mathrm{H}_{2}$ plasma treatment step after Ga deposition is presented in Fig. 10(a). First, at the $\mathrm{P}$ deposition step $(100 \mathrm{~W})$ a rise of $\mathrm{PH}_{3}$ concentration in the chamber leads to an increase of $\mathrm{PH}_{2}$ line intensity, which is accompanied by a decrease of the intensity of the $\mathrm{H}_{\alpha}$ line because $\mathrm{PH}_{3}$ ionization energy $(7.2 \mathrm{eV})$ is much lower compared to that of hydrogen $(16.5 \mathrm{eV})$. Addition of $\mathrm{PH}_{3}$ with a low ionization energy leads to redistribution of the electron energy in the plasma and therefore to a decrease of ionized hydrogen atoms concentration. ${ }^{20}$ Studying changes in the intensity of the $\mathrm{H}_{\alpha}$ hydrogen line is an indirect way to determine the variation of phosphine concentration. Next, during the purge step $(20 \mathrm{~W})$, the $\mathrm{H}_{\alpha}$ line intensity increases due to the drop of $\mathrm{PH}_{3}$ concentration in the chamber. Finally, at the $\mathrm{Ga}$ deposition step $(100 \mathrm{~W})$, a slight increase of the $\mathrm{PH}_{2}$ line intensity is observed because of the phosphorous etching in $\mathrm{H}_{2}$ plasma. The traces of phosphorous precursors during $\mathrm{Ga}$ deposition step obviously lead to uncontrollable GaP deposition.

To confirm this $\mathrm{P}$ etching effect, the phosphorous was deposited at the chamber walls by $\mathrm{PH}_{3}$ decomposition during $30 \mathrm{~s}$ at $100 \mathrm{~W}$. Then, the chamber was purged by $\mathrm{H}_{2}$ during 1 min without plasma. Next, the $\mathrm{H}_{2}$ plasma $(100 \mathrm{~W})$ etching was started. Time dependence of $\mathrm{H}_{\alpha}$ and $\mathrm{PH}_{2} \mathrm{OES}$ lines is presented in Fig. 9(b). The $\mathrm{PH}_{2}$ line was clearly observed in the plasma which intensity decreased during $20 \mathrm{~s}$ accompanied by the rise of the $\mathrm{H}_{\alpha}$ line intensity. The observed

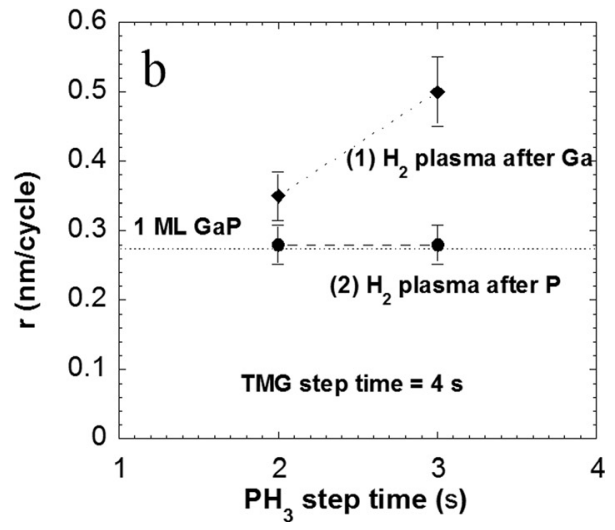

FIG. 8. Deposition rate $(r)$ as a function of TMG (a) and $\mathrm{PH}_{3}$ (b) deposition step time for GaP deposited with pulsed RF power (100 W) using $\mathrm{H}_{2}$ plasma treatment after Ga deposition step (1) and $\mathrm{H}_{2}$ plasma treatment after $\mathrm{P}$ deposition step. $\mathrm{PH}_{3}$ (a) and TMG (b) deposition step times were fixed to 2 and 4 s, respectively. The level of one GaP monolayer (ML) is also indicated. 

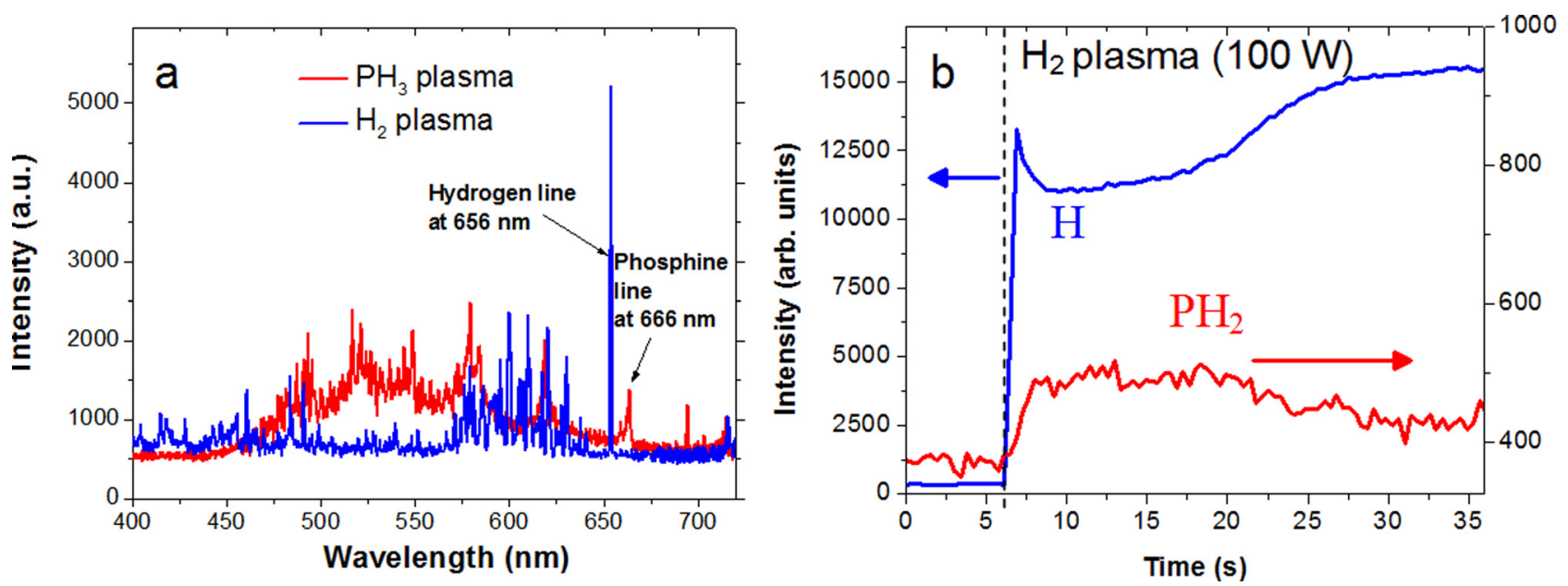

FIG. 9. (Color online) OES spectra of $\mathrm{H}_{2}$ and $\mathrm{PH}_{3}$ plasma (a). Time dependence of $\mathrm{H}_{2}(656 \mathrm{~nm})$ and $\mathrm{PH}_{2}(666 \mathrm{~nm})$ OES lines for $\mathrm{H}_{2}$ plasma treatment after $\mathrm{P}$ deposition during $30 \mathrm{~s}(\mathrm{~b})$.

behavior indicates a strong phosphorous etching effect which affects the GaP deposition process.

To avoid the negative influence of etching effect to the PE-ALD, the process was modified. Longer $\mathrm{H}_{2}$ plasma treatment steps $(100 \mathrm{~W})$ were introduced after the $\mathrm{P}$ deposition step to etch the phosphorous in excess before Ga deposition. Moreover, no $\mathrm{H}_{2}$ plasma treatment steps after $\mathrm{Ga}$ was used. The time dependence of $\mathrm{PH}_{2}$ and $\mathrm{H}_{\alpha}$ lines for this modified process is presented in Fig. 10(b). A decrease of $\mathrm{PH}_{2}$ and increase of $\mathrm{H}_{\alpha}$ lines intensity is observed during $\mathrm{H}_{2}$ plasma treatment steps indicating a removal of excess phosphorous, while no phosphorus precursor presence $\left(\mathrm{PH}_{2}\right.$ line) is observed during the Ga deposition step. This modified pulsed RF power process allows one to reach ALD like growth of GaP films with nonuniformity less than $5 \%$ for 3 in. substrates and less than $3 \%$ for $2 \mathrm{in}$. substrates. The results of optical measurements of the uniformity are presented in Fig. 11, where the distribution of the wavelength of reflection maximum as a function of distance for 3 in. Si substrates is shown. The position of the reflection maximum, which slightly depends on distance, was used to calculate the GaP film thickness. The thicknesses values correspond well to the one obtained by electron microscopy and are varied in narrow range indicating good film thickness uniformity.

\section{SUMMARY AND CONCLUSIONS}

Plasma enhanced atomic layer deposition approach allows one to obtain amorphous or microcrystalline GaP films at temperatures below $400{ }^{\circ} \mathrm{C}$. The transition from amorphous to microcrystalline structure could be obtained by the increase of the RF power, which increases the kinetic energy of the adsorbed atoms and their migration possibility. However, a significant increase of surface roughness appears for microcrystalline GaP films compared to the smooth surface of amorphous GaP.

A specific feature of the $\mathrm{GaP}$ growth mechanism was observed for higher RF power modes, namely, an accumulation of the phosphorous at the deposition chamber walls. The excess phosphorous in the chamber etched by the hydrogen plasma may interact with Ga precursors thus perturbing the ALD mode. The way to minimize this negative effect by an
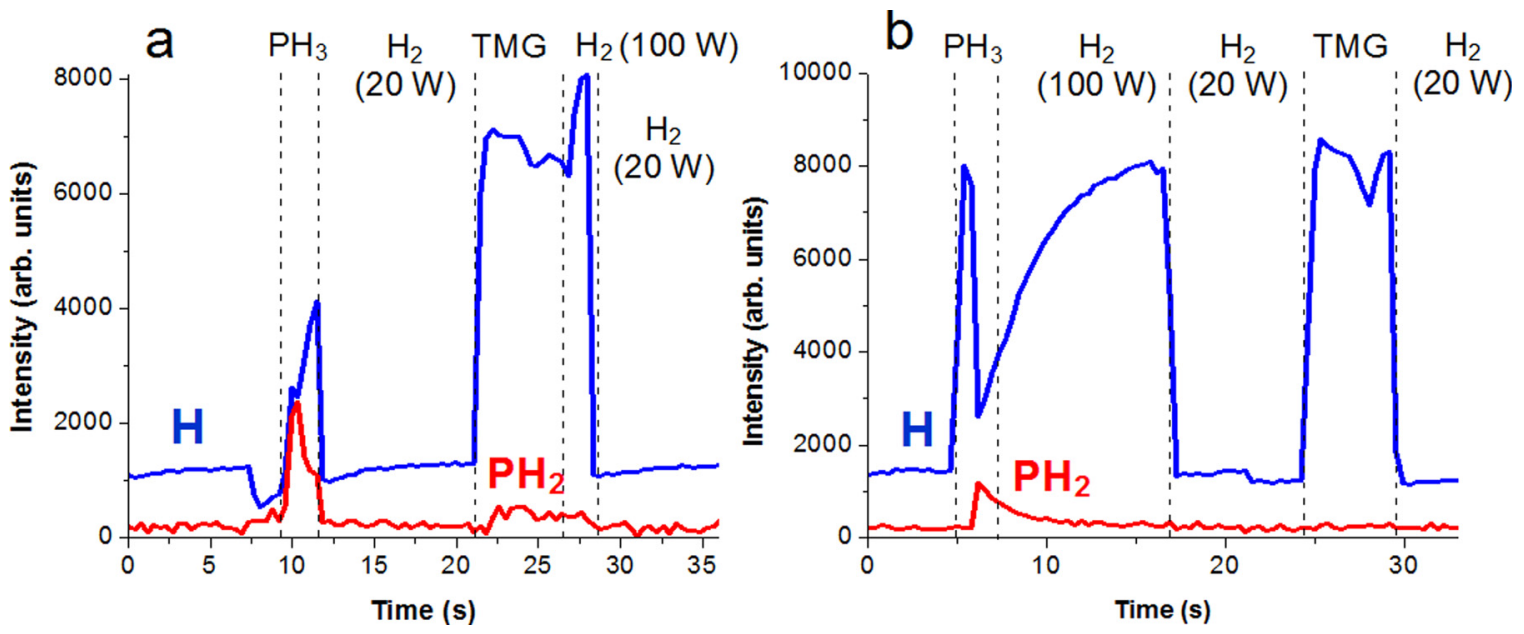

FIG. 10. (Color online) Time dependence of $\mathrm{H}_{\alpha}(656 \mathrm{~nm})$ and $\mathrm{PH}_{2}(666 \mathrm{~nm})$ OES lines for the processes with $\mathrm{H}_{2}$ plasma treatment step after Ga deposition step (a) and after P deposition step (b). 


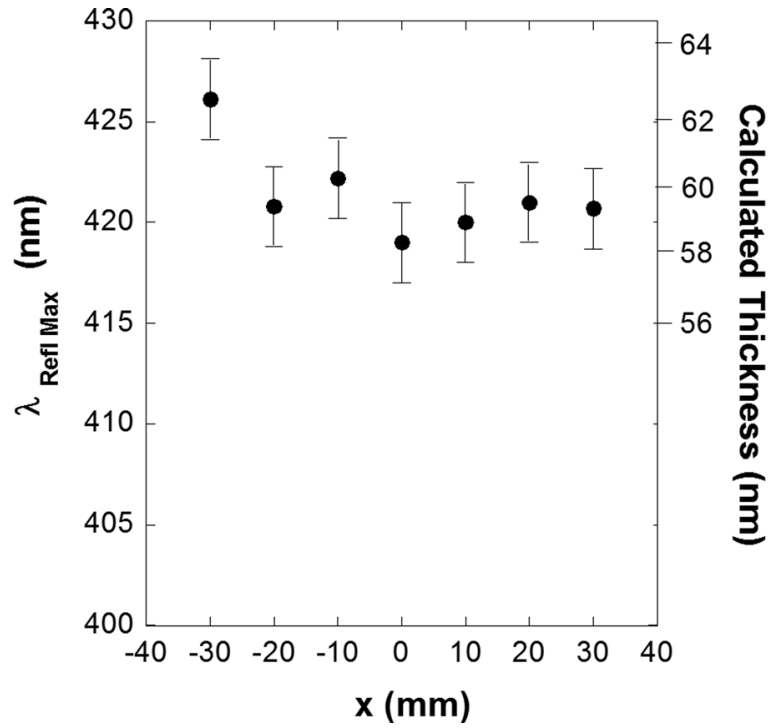

FIG. 11. Wavelength of the reflection maximum $\left(\lambda_{\text {Refl Max }}\right)$ vs distance for 3 in. Si substrates with $\mathrm{GaP}$ film deposited with $\mathrm{H}_{2}$ plasma treatment step after $\mathrm{P}$ deposition step. Calculated GaP film thickness, which corresponds to $\lambda_{\text {Refl Max }}$, is indicated on the left axis.

additional hydrogen plasma etching step after $\mathrm{P}$ deposition was proposed. Microcrystalline GaP films with good thickness uniformity (thickness within $\pm 5 \%$ for 3 in. wafer) and saturated deposition rate (at one monolayer per cycle) were obtained. No phosphine traces in the plasma during Ga deposition step were observed in this case. Further studies will be devoted to the improvement of the structural properties and morphology of $\mathrm{GaP}$ films grown on Si by plasma enhanced deposition.

\section{ACKNOWLEDGMENTS}

This work was supported by the Russian Scientific Foundation under Grant No. 17-19-01482. TEM characterizations were performed using equipment owned by the Federal Joint Research Center.

${ }^{1}$ S. M. Sze, Physics of Semiconductor Devices, 2nd ed. (Wiley, New York, 1981).

${ }^{2}$ H. Wagner, T. Ohrdes, A. Dastgheib-Shirazi, B. Puthen Veettil, D. König, and P. P. Altermatt, J. Appl. Phys. 115, 044508 (2014).

${ }^{3}$ W. C. Cooley and R. J. Janda, Handbook of Space-Radiation Effects on Solar-Cell Power Systems (NASA, Washington, D.C., 1963).

${ }^{4}$ M. Feifel, T. Rachow, J. Benick, and J. Ohlmann, IEEE J. Photovoltaics 6, 384 (2016).

${ }^{5}$ M. Sadeghi and S. Wang, J. Cryst. Growth 227-228, 279 (2001).

${ }^{6}$ S. L. Wright, H. Kroemer, and M. Inada, J. Appl. Phys. 55, 2916 (1984).

${ }^{7}$ J. P. André, J. Hallais, and C. Schiller, J. Cryst. Growth 31, 147 (1975).

${ }^{8}$ L. Samuelson, P. Omling, and H. G. Grimmeiss, J. Cryst. Growth 68, 340 (1984).

${ }^{9}$ J. M. Olson, M. M. Al-Jassim, A. Kibbler, and K. M. Jones, J. Cryst. Growth 77, 515 (1986).

${ }^{10}$ M. S. Sobolev, A. A. Lazarenko, E. V. Nikitina, E. V. Pirogov, A. S. Gudovskikh, and A. Yu. Egorov, Semicond. 49, 559 (2015).

${ }^{11}$ J. F. Geisz, J. M. Olson, D. J. Friedman, K. M. Jones, R. C. Reedy, and M. J. Romero, 31th IEEE PVSC (2005), p. 695.

${ }^{12}$ A. S. Gudovskikh, K. S. Zelentsov, A. I. Baranov, D. A. Kudryashov, I. A. Morozov, E. V. Nikitina, and J.-P. Kleider, Energy Procedia 102, 56 (2016).

${ }^{13}$ R. Varache, M. Darnon, M. Descazeaux, M. Martin, T. Baron, and D. Muñoz, Energy Procedia 77, 493 (2015).

${ }^{14}$ J. A. van Delft, D. Garcia-Alonso, and W. M. M. Kessels, Semicond. Sci. Technol. 27, 074002 (2012).

${ }^{15}$ J. C. Knights and R. A. Lujan, J. Appl. Phys. 49, 1291 (1978).

${ }^{16}$ C. Ozgit, I. Donmez, M. Alevli, and N. Biyikli, J. Vac. Sci. Technol., A 30, $01 \mathrm{~A} 124$ (2012).

${ }^{17}$ I. A. Morozov, A. S. Gudovskikh, D. A. Kudryashov, E. V. Nikitina, J.-P. Kleider, A. V. Myasoedov, and V. Levitskiy, J. Phys.: Conf. Ser. 741, 012088 (2016).

${ }^{18}$ M. Wihl, M. Cardona, and J. Tauc, J. Non-Cryst. Solids 8-10, 172 (1972).

${ }^{19}$ S. Hayashi, Solid State Commun. 56, 375 (1985).

${ }^{20}$ G. Bruno, M. Losurdo, and P. Capezzuto, J. Vac. Sci. Technol., A 13, 349 (1995).

${ }^{21}$ B. Xiao, S. Kado, S. Kajita, and D. Yamasaki, Plasma Phys. Controlled Fusion 46, 653 (2004). 